\title{
Más allá de la protesta. Música militante en Bogotá en los años setenta y la transformación de la "música colombiana"
}

Resumen: Este trabajo presenta un panorama de la música vinculada a la militancia de izquierda en Bogotá en la década de 1970 y explora las relaciones entre las prácticas musicales, las opciones estéticas y los marcos ideológicos partidistas. Argumenta que la transformación de la denominada "música colombiana" a finales de los sesenta fue impulsada en buena parte por la influencia ideológica del "campo maoísta". Toma como fuentes registros sonoros realizados por el autor, prensa, discografía y entrevistas.

Palabras clave: marxismo, canción protesta, música colombiana.

\section{Beyond protest. Leftist militancy in Bogotá in the 70s and the transformation of "Colombian music"}

Abstract: This article presents an overview of the music that was linked to leftist militancy in Bogotá in the 1970s, exploring the relationship between musical practices, aesthetic options and partisan ideological frameworks. It argues that the transformation of the so-called "Colombian music" in the late 1960s was largely driven by the ideological influence of the "Maoist camp". The article looks into sound recordings made by the author, press, discography and interviews.

Keywords: Marxism, protest song, Colombian music.

\section{Além do protesto. Música militante em Bogotá nos anos 70 e a transformação da "música colombiana"}

Resumo: Este trabalho apresenta um panorama da música ligada à militância de esquerda em Bogotá nos anos 70 e explora as relações entre práticas musicais, opções estéticas e estruturas ideológicas partidárias. Propõe-se que a transformação da chamada "música colombiana" no final da década de sessenta foi impulsionada em grande parte pela influência ideológica do "campo maoísta". Toma como fontes registros sonoros feitos pelo autor, imprensa, discografia e entrevistas.

Palavras-chave: marxismo, música de protesto, música colombiana.

Cómo citar este artículo: Carlos Miñana Blasco, "Más allá de la protesta. Música militante en Bogotá en los años setenta y la transformación de la 'música colombiana'”, Trashumante. Revista Americana de Historia Socia/15 [2020]: 150-172. DOI: 10.17533/udea.trahs.n15a07

Fecha de recepción: 30 de agosto de 2018

Fecha de aprobación: 9 de mayo de 2019

Carlos Miñana Blasco: Doctor en Antropología Social y Cultural por la Universitat de Barcelona. Profesor de la Universidad Nacional de Colombia, sede Bogotá.

.Correo electrónico cminanabl@unal.edu.co 


\title{
Más allá de la protesta. Música militante en Bogotá en los años setenta y la transformación de la "música colombiana"
}

\author{
Carlos Miñana Blasco
}

\section{Introducción}

$\mathrm{H}^{2}$ asta mediados de la década de los setenta el término "música colombiana" se asociaba a los bambucos, pasillos y danzas urbanas interpretados por duetos vocales, o grupos instrumentales. " La canción colombiana, en general, no tiene de campestre sino los temas literarios y en algunos casos los giros idiomáticos imitados por los poetas urbanos. Nació en las ciudades. La hicieron los poetas cultos, de moda, o con frecuencia también, se recortaban los versos de los semanarios hispanos". ${ }^{2}$ Diez años después este término se había ampliado inmensamente y allí cabían rajaleñas, guabinas a capela, redovas, porros chocoanos, bullerengues, entre otros ritmos.

Muchos y diversos fueron los factores y agentes que llevaron a enriquecer semántica y sonoramente el término "música colombiana”: intérpretes y compositores que exploraron y crearon en esos años desde sus búsquedas y apuestas; los festivales y concursos "folklóricos"; el trabajo pedagógico y artístico de centros como el Instituto Popular de Cultura de Cali o la Escuela Popular de Arte de Medellín; la labor del Instituto Colombiano de Cultura (COLCULTURA) y de investigadores profesionales y, en su mayoría, amateur, como los "folklorólogos" Guillermo Abadía (1912-2010) u Octavio Marulanda (1921-1997). ${ }^{3}$

En este trabajo pretendo explorar un factor poco considerado: la influencia de las ideas y del activismo político y cultural de los años setenta en la transformación

1. Egberto Bermúdez, "From Colombian 'National Song' to 'Colombian Song': 1860-1960”, Lied und Populäre Kultur / Song and Popular Culture 53 (2008): 167-261.

2. Hernán Restrepo Duque, Lo que cuentan las canciones: cronicón musical (Bogotá: Tercer Mundo, 1971) 94.

3. Carlos Miñana Blasco, "Entre el folklore y la etnomusicología. Sesenta años de estudios sobre música popular tradicional en Colombia", A Contratiempo. Revista de música en la cultura 11 (2000): 36-49. 
de la percepción y de las prácticas en torno a la "música colombiana”. Para ello voy a esbozar un panorama general de la actividad musical de los grupos asociados a la izquierda política, las diferentes tendencias ideológicas, y a sustentar que los planteamientos maoístas fueron claves en esa década para poner en escena la "música popular tradicional y regional” desde una crítica al folklorismo y a la visión urbana de la música colombiana.

El trabajo se basa en mi experiencia personal plasmada en notas y diarios, grabaciones de recitales, casetes grabados de forma casera que circularon en miles, discografia, entrevistas y fuentes documentales primarias (prensa, revistas, cancioneros, manifiestos y panfletos, programas de recitales) y secundarias.

En un país polarizado políticamente sigue presentándose, a pesar del reciente acuerdo de paz, persecución y exterminio a líderes de izquierda. Por ello, hablar de la influencia del marxismo en la música colombiana suscita suspicacias y sensibilidades; personas con una imagen pública y un éxito musical evitan hablar de esa época, puede ser incluso peligroso. A pesar de ello, considero importante hacerlo porque se ha construido una visión simplista y descalificadora de esos años. Pretendo contextualizar lo sucedido y mostrar cómo gracias a estos músicos se pudieron visibilizar y mirar de otra forma las músicas campesinas e indígenas de la Colombia diversa y real; buena parte de la "colombianidad" de hoy es fruto de sus rupturas y apuestas.

Señalar que un grupo era, por ejemplo, maoísta no significa que fueran militantes o cuadros orgánicos, sino que sus integrantes mostraban afinidad ideológica con el maoísmo como enfoque general. Incluso, algunos músicos participaron en proyectos de facciones políticas o ideológicas enfrentadas — militantes de la izquierda colaboraron con el Partido Conservador-, y músicos del movimiento hippie o del rock participaron en giras internacionales o grabaciones discográficas de la izquierda.

No obstante, la música militante marcó profundamente la vida musical y cultural desde mediados de los años sesenta hasta finales de los ochenta, especialmente en Bogotá. A diferencia de Chile, Cuba o Nicaragua, países en los que hubo confluencia o articulación de la izquierda para la toma del poder, el movimiento musical militante se produce en Colombia en un momento de una gran fragmentación. Este escenario diverso y móvil de alianzas y confrontaciones ideológicas resulta perfecto para explorar las sutiles y complejas relaciones entre los referentes ideológicos y las opciones estéticas y musicales, es decir, las relaciones entre arte y política en una época en la que las artes eran explícita e intencionalmente un arma más de la lucha política.

Los escasos escritos sobre la música de protesta y militante en Colombia suelen abordarla trasladando planteamientos y discursos sobre la nueva canción latinoamericana. Además, el fenómeno denominado "canción protesta" en Colombia ha tenido varias reediciones nostálgicas en años posteriores por parte de la industria discográfica bajo el nombre de "canción social" o "los años maravillosos"; los 
trabajos historiográficos han sido muy generales o de divulgación, ${ }^{4}$ han construido una imagen centrada en la producción discográfica comercial —evitada por los militantes - y donde están ausentes la mayoría de los grupos cuya actividad se movía ampliamente en mítines sindicales, campesinos, indígenas y políticos. Los únicos trabajos de calado y con buen manejo de fuentes son tres tesis doctorales. La primera aborda los procesos de recontextualización del folklore musical que se produjo en los años ochenta a través de la obra de un cantautor y un grupo musical del Valle del Cauca, y un grupo de Bogotá, Nueva Cultura; se basa en la producción discográfica de los ochenta y en entrevistas. ${ }^{5}$ La segunda también muy centrada en la producción discográfica se ubica principalmente en la década de los sesenta. ${ }^{6}$ La tercera tesis doctoral explora la génesis de las nuevas músicas colombianas, pero curiosamente no menciona la música ligada a la militancia. ${ }^{7}$

¿Fueron los años setenta una década perdida? ¿Por qué y cómo estudiar una música que nunca se grabó, no se escuchaba en la radio, no aparecía en la televisión y cuyos conciertos no se anunciaban en la prensa? Sarah Thornton ha planteado cuatro criterios para otorgar importancia histórica a un evento en el marco de los media, pero con este tipo de movimiento que eludió los medios es necesario considerar otros. ${ }^{8}$ Giras por todo el país y con salas abarrotadas no aparecieron en la prensa; la mayoría de la música nunca se grabó o se hizo mucho después, o circuló en grabaciones caseras de casetes; decenas de canciones se entonaron en mítines, huelgas, manifestaciones, universidades, tomas de tierras, peñas, entre otros escenarios; sus textos se multiplicaron cientos de miles de veces en cancioneros impresos, en rústicas copias o en cuadernos; canciones que se aprendían en colegios públicos y religiosos, en las carpas de los huelguistas, en los cursos sindicales. Juan Pablo González Rodríguez ha señalado cómo la memoria de determinadas canciones no siempre corresponde con sus índices de popularidad o mediatización, además de la circulación "paramediática" de algunos tipos de música.?

4. Miryam Ibeth Robayo Pedraza, "La canción social como expresión de inconformismo social y político en el siglo XX”, Calle 1410.16 (2015): 54-67. El trabajo de Álvaro Tirado Mejía, excelente para contextualizar la época, en el campo de la música se basa en escasas fuentes secundarias de la nueva ola y el rock. Álvaro Tirado Mejía, Los años sesenta (Bogotá: Debate, 2014).

5. Ana María Ochoa Gautier, "Plotting Musical Territories. Three Studies in Processes of Recontextualization of Musical Folklore in the Andean Region of Colombia" (PhD dissertation in Ethnomusicology and Folklore, Indiana University, 1996).

6. Joshua Katz-Rosene, "From Protest Song to Social Song: Music and Politics in Colombia, 19662016" (PhD dissertation in Music, City University of New York, 2017).

7. David Fernando García González, "Bandas sonoras de la colombianidad. Un estudio de los íconos musicales de la nación en el siglo XXI" (Tesis de doctorado en Ciencias Humanas y Sociales, Universidad Nacional de Colombia, 2016).

8. Sarah Thornton, "Strategies for Reconstructing the Popular Past", Popular Music 9.1 (1990): 87-95.

9. Juan Pablo González Rodríguez, "Musicología popular en América Latina: síntesis de sus logros, problemas y desafios”, Revista Musical Chilena 195 (2001): 38-64; Juan Pablo González Rodríguez y Claudio Rolle, "Cristalización genérica en la música popular chilena de los años sesenta", Música popular en América Latina. Actas del II Congreso Latinoamericano IASPM, ed. Rodrigo Torres 


\section{Canción protesta, música andina y teología de la liberación}

En Colombia desde el siglo XIX distintos sectores han expresado a través de la copla, la décima y las canciones sus críticas sociales y políticas. En un país diverso geográfica, étnica y culturalmente como Colombia, estas expresiones también han sido heterogéneas. Por esta razón, movimientos como el de la nueva canción latinoamericana tuvieron impacto muy diferente en las regiones y ciudades colombianas. Más que una visión sobre esta Colombia diversa, pretendo reconstruir el fenómeno en Bogotá, ciudad que en 1966 rondaba los dos millones de habitantes y en la que la población inmigrante representaba el 51,39\%, es decir, Bogotá era un crisol de las regiones.

A finales de los años sesenta el descontento de la juventud generó movilizaciones estudiantiles y movimientos contraculturales en casi todo el planeta entre los que la canción jugó un papel importante, aunque se expresó de diferentes maneras (rock, himnos revolucionarios, hipismo, psicodelia, neofolk) y recibió diferentes nombres: Movimiento Nuevo Cancionero en Mendoza (Argentina, 1963), nueva canción chilena (1965), entre otros. En Cuba, Puerto Rico y Colombia, entre otros países, se denominó inicialmente "canción protesta". En Bogotá surge de la articulación de cinco procesos relativamente diferenciables pero interconectados: el nadaísmo, la protesta "comercial”, la música andina de Suramérica, la música de las comunidades de base ligada a la teología de la liberación, y la protesta militante. ${ }^{10} \mathrm{Me}$ centraré en la música vinculada a la militancia, pero primero caracterizaré brevemente los otros cuatro procesos.

El movimiento literario e iconoclasta denominado nadaísmo, iniciado en Medellín en 1958, tendrá su mayor auge a comienzos de los setenta. En lo musical se concretó en las canciones de Pablus Gallinazo (Gonzalo Navas Cadena, 1943), inspiradas en la balada romántica y la música andina urbana del centro del país (guabina canción, bambuco) con una emisión vocal desganada, musicalmente elemental y literariamente irreverente. La circulación de esta música fue principalmente discográfica, en festivales y conciertos. Su trabajo ejerció una notable influencia en la canción protesta comercial. Integrantes del movimiento nadaísta estuvieron detrás del primer y segundo Festival de la Canción Protesta "Coco de oro" en 1970 y 1971, en la isla de San Andrés.

(Santiago de Chile: IASPM, 1999) 365-374. Respecto al contexto socioeconómico, político y cultural del periodo 1968-1982, véase Miguel Ángel Urrego Ardila, Intelectuales, Estado y Nación en Colombia. De la guerra de los Mil Días a la constitución de 1991 (Bogotá: Universidad Central, 2002); César Augusto Ayala Diago, "Colombia en la década de los años setenta del siglo XX", Anuario Colombiano de Historia Social y de la Cultura 30 (2003): 319-338; Mauricio Archila Neira, Idas y venidas, vueltas y revueltas. Protestas sociales en Colombia, 1958-1990 (Bogotá: Instituto Colombiano de Antropología e Historia, 2003); Leopoldo Múnera Ruiz, Rupturas y continuidades: poder y movimiento popular en Colombia, 1968-1988 (Bogotá: Universidad Nacional de Colombia, 1998).

10. Sigo de forma muy libre a Katz-Rosene, e incluyo mis aportaciones. La denominación "comercial" y "militante" corresponde a un etiquetado mío que tiene cierto anclaje en los discursos de la época. 
Un segundo proceso se origina en Bogotá. En 1966 Radio Todelar lanza “El club del clan", un programa copiado del canal 13 de la televisión argentina, y poco después, Alfonso Lizarazo hará lo mismo en Radio 15 de Caracol. Estos programas conectaron a Bogotá con la nueva ola y el rock. ${ }^{11}$ Lizarazo creó un sello disquero asociado con el nadaísmo. El agotamiento comercial de la nueva ola a finales de los sesenta llevó a Lizarazo y a otros productores a explorar otras tendencias como la música tropical, la psicodelia y la canción protesta; promovieron adolescentes como los hermanos Valencia: Ana y Jaime (1969-1986), o Norman y Darío con el LP Las primeras protestas (1969) quienes venían del grupo de la nueva ola, Los Yetis. Él va a ser uno de los organizadores del III Festival de la Canción Protesta en 1972 en Barranquilla. La difusión de esta música fue principalmente por radio y televisión, así como a través de la industria discográfica, festivales y conciertos masivos orientados a los jóvenes. Musicalmente se nutrían de la balada, del bambuco urbano tradicional, del pop norteamericano y de la incipiente nueva canción latinoamericana. Estos adolescentes tenían un débil posicionamiento político. La canción protesta colombiana y nadaísta como fenómeno comercial tuvo su momento estelar a finales de los sesenta y comienzos de los setenta, pero va a ser desplazada por la avalancha de la producción chilena en el exilio, y la argentina y cubana, a través de sellos como Orbe, CBS y Fonoson que desde 1974 irrumpen bajo la denominación de canción social, "la bella música que no se radiodifunde". ${ }^{12}$

La música andina latinoamericana, caracterizada por quenas, charangos, bombos y zampoñas, tanto en su versión hippie como en la folklorista configuró también el paisaje sonoro bogotano. ${ }^{13}$ Proliferaron numerosos imitadores, aunque hubo creaciones locales que fusionaron el rock-folk con música andina latinoamericana y colombiana, como el grupo Génesis (1972-1992) liderado por Humberto Monroy (19451992), exintegrante de los Speakers (1964-1969) y que ahora estaba en las filas del hipismo. Un grupo que conectó la música andina latinoamericana con las bandas de flautas del suroccidente andino colombiano fue Chimizapagua (1976-1992).

También hay que señalar el papel de los religiosos y laicos católicos y protestantes vinculados a la teología de la liberación o a comunidades cristianas de base y un sector de la jerarquía eclesial. Si bien en general eran pacifistas, algunos se radicalizaron y engrosaron las filas de la guerrilla del Ejército de Liberación Nacional (ELN). Los

11. Las relaciones entre el rock, el hipismo y la izquierda en Colombia fueron diversas, pero en general desde la militancia se criticaban y combatían; véase Tirado Mejía 170. Desde 1970 el hipismo, al igual que la nueva ola desde 1967, fue promovido comercialmente desde la prensa, la industria y la publicidad. Federico García Barrientos, Publicidad, rock and roll, contracultura y política: Colombia 1967-1974 (del giro del consumo al del mercado electoral) (Medellín: Universidad Pontificia Bolivariana, 2016) 121-249.

12. "Discos Orbe Ltda. presenta la bella música que no se radiodifunde", El Tiempo (Bogotá) 15 de agosto de 1979: 7B.

13. Fernando Rios, "La Flûte Indienne: The Early History of Andean Folkloric-Popular Music in France and its Impact on Nueva Canción", Latin American Music Review / Revista de Música Latinoamericana 29.2 (2008): 145-181; Joshua Katz-Rosene, "Discourse in Música Latinoamericana Cultural Projects from Nueva Canción to Colombian Canción Social”, Volume! 11.2 (2015): 65-83. 
grupos guerrilleros y clandestinos no fueron muy visibles en la actividad musical bogotana, pero sí los movimientos religiosos de izquierda. ${ }^{14}$

El quinto proceso, la producción colombiana ligada a la militancia de izquierda, ha sido el menos documentado, pero fue el más diverso por la multiplicación de sus facciones, y el más influyente políticamente por el ascenso de las luchas estudiantiles, campesinas, indígenas y sindicales. Cada partido político o facción se esforzó por crear un "Frente" o una "Brigada" cultural, los cuales tomaron casi siempre como base el teatro universitario. ${ }^{15}$

\section{La canción militante y revolucionaria}

La nueva canción en Colombia no solo pretendió oponerse a las tendencias comerciales, ${ }^{16}$ sino en muchos casos, como veremos, diferenciarse de la nueva canción latinoamericana y de otras expresiones musicales de la misma izquierda. Ser de izquierda a finales de la década de los sesenta y comienzos de los setenta era la marca de identidad de la juventud colombiana, y las ideas y vocabulario marxistas permeaban la vida cotidiana. No obstante, las fronteras entre las tendencias de la izquierda, en la práctica, nunca fueron muy claras, así los debates ideológicos llegaran a sutiles matices y a apasionadas confrontaciones y descalificaciones; la clandestinidad contribuyó a que incluso algunas personas no supieran exactamente dónde estaban militando.

Los militantes de distintas tendencias y los no militantes coincidían en los objetivos políticos: el capitalismo era un sistema injusto que promovía y se alimentaba de la desigualdad social; había que derrocarlo e instaurar una sociedad igualitaria socialista. El proletariado y en general los desposeídos debían hacer la revolución, pues eran los más interesados en ello, pero se necesitaba la organización y la coordinación de alguna estructura o partido, un liderazgo y una claridad en el cómo. Todos percibían la toma del poder como algo cercano. Las divergencias estaban en el cómo llegar allá y en quién debería liderar el proceso, es decir, en los niveles estratégico y táctico. En los sesenta y buena parte de los setenta la lucha armada era ampliamente compartida como estrategia, incluso se veía como un mal menor necesario por parte de los pacifistas; sin embargo, había diversidad en la forma de entenderla, en su protagonismo y en su articulación con otras formas de lucha.

14. Juan José Guerrero Pérez, La canción protesta latinoamericana y la Teología de la Liberación: estudio de género musical y análisis de vínculo sociopolítico y religioso (1968-2000) (Caracas: Monte Ávila, 2005).

15. Mayra Natalia Parra Salazar, iA teatro camaradas! Dramaturgia militante y política de masas en Colombia (1965-1975) (Medellín: Fondo Editorial FCSH, 2015); Paulo César León Palacios, "Una experiencia estética de lo político: el teatro en Bogotá durante los años 1960 y 1970", Historelo. Revista de Historia Regional y Local 9.17 (2017). DOI: 10.15446/historelo.v9n17.54732 (17/02/2018); Consuelo Moure de Ramírez, "El teatro universitario colombiano 1968-1975”, (Ensayo, Escuela Nacional de Arte Dramático, 1989). http://es.scribd.com/doc/201382621/ElTeatro-Universitario-Colombiano-1968-1975 (04/02/2018).

16. Jane Tumas-Serna, “The 'Nueva Canción’ Movement and Its Mass-Mediated Performance Context”, Latin American Music Review / Revista de Música Latinoamericana 13.2 (1992): 139. 
También existieron diferencias en torno a la participación en elecciones. El papel de la dirigencia y su conformación fue otro campo de debate al igual que el sector social que lideraría el proceso, las alianzas con otros sectores y las relaciones internacionales. En los setenta, a pesar de la multiplicación de organizaciones y facciones, había tres grandes posiciones en cuanto a lo estratégico y lo táctico: la del Partido Comunista Colombiano (PCC), la trotskista o socialista y la maoísta.

La tendencia liderada por el PCC, marxista, leninista, pro soviética y pro cubana, proponía la combinación de todas las formas de lucha para llegar al poder. El proletariado, los obreros, liderarían la revolución. En el campo cultural su actividad fue definitiva para la historia del teatro colombiano y tuvo un gran impacto internacional. ${ }^{17}$ Musicalmente, y coherentes con su estrategia de combinar todas las formas de lucha, fueron muy flexibles y promovieron la participación de todo tipo de músicos en sus eventos. Por la Casa de la Cultura (1966) y luego por el teatro La Candelaria pasaron "cantantes de protesta, baladistas, folcloristas, poetas y espontáneos" en las "peñas folclóricas", ${ }^{18}$ a semejanza de la Peña de los Parra (Chile, 1965). Un año después del que se creó en Cuba (1967) organizan el Centro Nacional de la Canción Protesta (CNCP, 1968-1973), que promovería el Primer Festival de la Canción Protesta (1970) y publicaría un cancionero. ${ }^{19}$ Vincularon a músicos del sector académico, como hizo la Unidad Popular en Chile; ${ }^{20}$ produjeron espectáculos a la manera de las cantatas populares chilenas; realizaron anualmente grandes festivales abiertos al público (Festival de Voz Proletaria); organizaron delegaciones para representar a Colombia en numerosos festivales en los países del bloque soviético. La producción musical es dificil caracterizarla dentro de un estilo: fue diversa, incluía baladas, canciones que imitaban los repertorios de la canción revolucionaria europea y la nueva canción latinoamericana, música colombiana al uso en esa época (bambuco y guabina urbanos) y llanera. A pesar de su importante activismo musical, considero que su eclecticismo estético, su oportunismo táctico y la escasa intervención de los dirigentes en el manejo de la actividad artística no facilitaron que todo ese activismo produjera una transformación de la música colombiana en alguna dirección. ${ }^{21}$

En otra vertiente estaban los trotskistas-socialistas, de base universitaria, quienes adoptaban una perspectiva crítica de los nacionalismos, y con una visión urbana e internacionalista de la revolución. Inicialmente opuestos a la participación en la

17. Claudia María Maldonado C., "La Candelaria de Bogotá en el paisaje teatral colombiano" (Memoria de Master investigativo, Université Sorbonne-Nouvelle, Paris III, 2005).

18. Gustavo Gac Artigas y Perla Valencia Moncada, Antología de canción protesta (Bogotá: Editorial Colombia Nueva, 1970). Cantautores vinculados a esta línea fueron Juan Sebastián, Jaime Caycedo Turriago (1953), Carlos Parada Arango ("Charlie Boy”, 1942), Kemel George González, Alejandro Gómez Roa, Jairo Ojeda, entre otros, y el dueto Los Hermanos Escamilla.

19. Robin D. Moore, Music and Revolution. Cultural Change in Socialist Cuba (Berkeley: University of California Press, 2006) 148; Gac Artigas y Valencia Moncada.

20. Fueron los casos de Francisco Zumaqué (1945), Samuel Bedoya (1947-1994) y Raúl Rosero (1948).

21. Parra Salazar 107-108. 
"farsa electoral”, en 1977 lanzan a Kemel George González como precandidato presidencial. ${ }^{22}$ George había liderado poco antes la Brigada Socialista de la Canción, que produjo un único LP titulado Rompiendo el silencio, con canciones de su autoría. Criticaban a la Unión Soviética y al PCC y, para ellos, los maoístas tenían una visión provinciana y feudal de la sociedad por su énfasis en el campesinado. En Bogotá, el Centro Latino de la Cultura (Acto Latino, grupo de teatro, 1967), inicialmente de tendencia camilista derivaría en estos años hacia el trotskismo y después hacia el M19. Allí surgirá el grupo musical Son Latino, la revista Muro Latino (1972) y un grupo de títeres, entre otros.

Hubo también grupos muy influyentes en esta época, varios de cuyos integrantes militaron o fueron afines a distintas tendencias, como es el caso del Yaki Kandru (1970-1983 en Bogotá; luego seguiría en forma de dueto en el exilio en París) liderado Jorge López Palacio (contratenor y estudiante de antropología en la Universidad Nacional de Colombia). El Yaki es un grupo urbano pionero en la interpretación de música indígena amazónica y americana. López, aunque militó en varias organizaciones, nunca fue maoísta; no obstante, su peculiar enfoque permite relacionarlo con este ideario y con su estética, como argumentaré más adelante. La práctica musical y el discurso de López, explícitamente marxista, fue crítico e iconoclasta, incluso con las posiciones estéticas y políticas de las organizaciones en que militaba.

A diferencia de lo que pasó en Chile, ${ }^{23}$ buena parte de la canción militante colombiana no se orientó al latinoamericanismo, sino a otro tipo de nacionalismo. Y lo que hizo despegar a la música militante de la imitación de los estilos de la nueva canción latinoamericana fue principalmente la tendencia maoísta.

\section{El campo maoísta}

El maoísmo en Colombia desde su surgimiento, sus trayectorias, divergencias y alianzas ha sido caracterizado por varios autores. ${ }^{24}$ Nos centraremos en el denominado campo ML (1964), concebido como un campo ideológico, ético y político más que como un partido o grupo de partidos. ${ }^{25}$

22. Martha Cecilia García Velandia, "El presente es de lucha: el futuro, socialista", Controversia 190 (2008): 108.

23. Juan Pablo González Rodríguez, Pensar la música desde América Latina. Problemas e interrogantes (Santiago: Ediciones Universidad Alberto Hurtado, 2013) 217.

24. Archila, Idas y venidas; Mauricio Archila Neira, "El maoísmo en Colombia: La enfermedad juvenil del marxismo-leninismo", Controversia 190 (2008): 147-196; Rodolfo Antonio Hernández Ortiz, "Los orígenes del maoísmo en Colombia: la recepción de la Revolución de Nueva Democracia 19491963" (Tesis de pregrado en Historia, Universidad Nacional de Colombia, 2016); Frank Molano Camargo, "El campo es leña seca lista para arder. La Liga Marxista Leninista de Colombia, 1971-1982", Anuario Colombiano de Historia Social y de la Cultura 44.2 (2017): 137-170.

25. Archila, "El maoísmo". 
1. "El maoísmo reivindica la lucha armada en la modalidad de guerra popular prolongada como se vivió en la experiencia china — fórmula opuesta al modelo insurreccional soviético y al foco cubano-.${ }^{26} \mathrm{~A}$ mediados de los setenta el campo ML se orienta al trabajo de masas y pone en segundo plano la lucha armada. Electoralmente fueron abstencionistas, aunque con el tiempo se fueron acercando a la "criticada fórmula de la 'combinación de las formas de lucha"” del PCC y participaron en elecciones. ${ }^{27}$

2. "Los fracasos en la implantación de los focos guerrilleros" los llevan a estudiar la realidad colombiana. Por eso desde mediados de los setenta va a ser fundamental el papel del marxismo "en las nacientes ciencias sociales en Colombia y la labor editorial que desplegó la izquierda". ${ }^{28}$

3. "El maoísmo mira $[\ldots]$ a Colombia, como sociedad no plenamente 'capitalista' con remanentes 'feudales". Por ello plantea la construcción de una "nueva democracia" haciendo alianzas con "sectores supuestamente progresistas de una burguesía catalogada de "nacional' [...] En esto los ML coincidieron con el PCC, pero no todos, pues el PC-ML desechaba la existencia de dicha burguesía [...] mientras la Liga ML y el Moir fueron más ortodoxos en este aspecto". ${ }^{29}$

4. "El maósmo termina reivindicando al campesino como la principal fuerza revolucionaria". Esto, ligado a la desconfianza en la intelectualidad pequeñoburguesa, va a llevar a una actitud "pedagógica" y a "una perspectiva paternalista-vanguardista, pues el campesinado, o el pueblo en general, por sí solo no podía hacer la revolución". 30

5. Como contrapeso al vanguardismo de los intelectuales, el maoísmo se acompañaba de "una gran orientación ético-política de "servir al pueblo", de tratar de vivir como él, de construir una ciencia "popular", de reconocer sus tradiciones y folklore. Esta orientación ética implicaba "una moral espartana de sacrificio material y afectivo" que evitaba las bebidas alcohólicas, las drogas y la fiesta, y daba a la vida militante un "sabor religioso", sacrificial, a pesar de ser formalmente ateos y hostiles al cristianismo. ${ }^{31}$

6. En lo cultural el maoísmo se orientó principalmente por las tesis de las Intervenciones en el foro de Yenán sobre arte y literatura de Mao TseTung de 1942.32 Además del frente militar, era necesario crear un "frente cultural", una "nueva cultura" "de calidad" que hiciera contrapeso a la "cantidad" de oferta cultural de "los reaccionarios chinos". ${ }^{33}$ Respecto al "para quién se hacen nuestras obras artísticas y literarias" (obreros, campesinos, soldados, cuadros y

26. Los planteamientos ideológicos no siempre resultaron coherentes con las prácticas. Por ejemplo, "la paradoja de las FARC, que siendo prosoviéticas siguieron el modelo chino, mientras el EPL, rígido maoísta durante años, se acercó a la práctica del foquismo”. Archila, "El maoísmo” 168.

27. Archila, "El maoísmo" 169.

28. Archila, "El maoísmo" 172.

29. Archila, "El maoísmo" 172.

30. Archila, "El maoísmo" 177-178.

31. Archila, "El maoísmo" 179-182.

32. Mao Tse-tung, Sobre la nueva democracia. Intervenciones en el foro de Yenán sobre arte y literatura. Sobre el tratamiento correcto de las contradicciones en el seno del pueblo. Discurso ante la Conferencia Nacional del Partido Comunista de China (Pekín: Ediciones en Lenguas Extranjeras, 1972).

33. Tse-tung 124. 
pequeña burguesía), Mao plantea que es necesario "comprenderlos y conocerlos a fondo", 34 conocer el "rico y vivo lenguaje de las masas", "sufrir un largo, e incluso penoso, proceso de temple". ${ }^{35}$ No se trata de "elevar" a los obreros y campesinos a la "altura" de la intelectualidad pequeñoburguesa, "sino elevar el arte y la literatura en la dirección en que avanzan los propios obreros, campesinos y soldados, en la dirección que avanza el proletariado". ${ }^{36}$

7. La segunda fuente doctrinal para el trabajo cultural provino del texto "Sobre la nueva democracia” (1940). ${ }^{37}$ La "nueva cultura" debía ser "nacional, científica y de masas". Lo nacional implicaba la valoración de lo propio y la asimilación crítica de lo foráneo. Lo científico Mao lo concretaba en que la cultura "está contra toda idea feudal y supersticiosa y por la búsqueda de la verdad en los hechos, por la verdad objetiva y por la unidad entre teoría y práctica", contra el "idealismo reaccionario" y las "doctrinas religiosas". ${ }^{38}$

El programa era muy claro para los militantes: la construcción de una estética popular junto con el pueblo. Un programa, además, que - a pesar de su ateísmocompartía algunas sensibilidades con la teología de la liberación y sus consignas de "servicio a los pobres" e "inserción" y con el movimiento de curas obreros. Un programa que mostraba afinidades con la epistemología de la etnografía en un momento en el que se crearon las carreras de antropología en Bogotá (Universidad de los Andes, 1964, y Universidad Nacional de Colombia, 1966).

\section{Prácticas musicales y discursos afines al campo maoísta en Bogotá}

Desde el punto de vista cultural el campo maósta se concretó en la práctica en dos grandes tendencias. La primera se organizó como el Movimiento Obrero Independiente y Revolucionario (MOIR, 1970) que no surgió de una disidencia del PCC, sino del Movimiento Obrero Estudiantil y Campesino (MOEC) en Medellín. La segunda apareció en torno a la esfera de un primer Partido Comunista de Colombia Marxista Leninista (PCC-ML, 1965) y de sus disidencias y fragmentaciones posteriores - Tendencia Marxista Leninista Maoísta, el Partido Comunista de Colombia-ML Línea Proletaria, los Comandos Pedro León Arboleda, la Liga Marxista Leninista (Liga ML)-.

\subsection{El Son del Pueblo: entre Shakespeare y el son cubano}

En la Universidad de los Andes, una universidad de élite, y también con actores provenientes de la Universidad Nacional de Colombia y de la Universidad Libre se constituyó en 1967 la brigada de Trabajadores del Arte Revolucionario (TAR),

\footnotetext{
34. Tse-tung 129-131.

35. Tse-tung 133-135.

36. Tse-tung 153-154.

37. Tse-tung 75-109.

38. Tse-tung 103-108.
} 
formando parte del Frente de la Cultura y bajo la dirección de Ricardo Camacho. Se consolidó como grupo de teatro en 1973 como Teatro Libre de Bogotá y se vinculó orgánicamente al MOIR. Su director, Ricardo Camacho, en una entrevista muestra cómo incorporaron las orientaciones de las Intervenciones en el foro de Yenán, pero también las tensiones con su formación "pequeñoburguesa”, como se diría en esa época, y su distancia con el teatro La Candelaria:

Fundamos este teatro porque queríamos hacer un grupo independiente que estuviera dedicado básicamente al teatro popular, a un teatro que sirviera de herramienta en la lucha por la transformación de la sociedad, inmerso en el proceso político, y que tendría su público principal en las masas trabajadoras $[\ldots]$ y, eso era muy importante, nos interesaba el teatro de autor. No hay que olvidar que fuimos educados en una facultad de literatura y filosofia, estudiando los clásicos y la literatura universal; por lo tanto, esto de la creación colectiva chocaba con esa formación. ${ }^{39}$

El Teatro Libre pronto fue orientando su trabajo hacia el teatro de autor y hacia obras clásicas como El rey Lear de Shakespeare (1978), con lo que tomaba distancia de las propuestas de creación colectiva y del "panfleto" que invadía el teatro universitario.

Antorcha fue el grupo musical en torno al Teatro Libre como parte del Frente Cultural, ${ }^{40}$ integrado por estudiantes de la Universidad de los Andes y liderado por Ricardo de los Ríos — violín, guitarra y voz-, que interpretaba canciones de la nueva canción latinoamericana. A ese grupo llega César Mora (1950), un estudiante de filosofia de la Universidad Nacional proveniente de Cali, quien los convenció de cambiar el estilo hacia el son, la guajira, el bolero y la guaracha. De esta forma se constituye el Son del Pueblo (1974), una especie de charanga simplificada (tiple en reemplazo del tres cubano, guitarras, bajo, violín, flauta traversa, voces y percusión). El Son está vinculado al Teatro libre y los músicos son actores, lo que implica actuar y musicalizar los montajes teatrales; no obstante, va tomando vida propia y organizando un recital autónomo que alterna con las obras de teatro. El repertorio se nutre de las guarachas y guajiras de Carlos Puebla (1907-1989), el "cantor de la revolución cubana”, y de sus propias canciones.

En ese proceso fue definitiva la participación en la huelga del ingenio azucarero de Riopaila en 1976. Su estancia con los corteros de caña los llevó a componer —a imitación de la Cantata de Santa María de Iquique (1969) del chileno Luis Advisuna cantata en ritmos cubanos que titularon "Los cantos del cañal". La cantata concluía con una composición de Gustavo Martínez y letra de César Mora que

39. "Contra viento y marea. Entrevista de Patricia Jaramillo Vélez a Ricardo Camacho". http:// www.teatrolibre.com/descargas/Contra-viento-y-marea.pdf (20/02/2017).

40. Para esta sección me baso en las entrevistas publicadas a César Mora en Tribuna Roja y en el folleto que acompaña el CD Cantos de lucha, editado por Tribuna Roja (Bogotá). Antorcha (1972) se conforma con integrantes de dos grupos anteriores, Esfera (1967) y Comuneros (1971), en los que participaron Carlos Riaño (el cantautor emblemático del MOIR) y Gustavo Martínez, cofundador del Son del Pueblo. 
inicia como un bolero cubano y concluye como un currulao colombiano. Este currulao, no obstante, era mucho menos fiel a la rítmica y melódica del Pacífico colombiano que los aires cubanos. Sin embargo, se intentó darle un "cierre" y un clímax colombiano a una cantata con una estética eminentemente cubana. ${ }^{41}$

Son del Pueblo realizó dos giras nacionales llenando teatros emblemáticos como el Jorge Eliécer Gaitán de Bogotá, Pablo Tobón de Medellín, Los Fundadores de Manizales, el Teatro Municipal de Cali, y varias internacionales por Venezuela, Ecuador, China, Europa y Estados Unidos. Las giras eran con el Teatro Libre y, paralelamente, presentaban su espectáculo musical. Como dice Mora "éramos el brazo cultural del MOIR. Cuando se necesitaba nuestra presencia, allí estábamos". ${ }^{42}$ Desarrollaron una intensa actividad musical. Tocaban en teatros, huelgas, sindicatos, universidades y, especialmente, acompañaban los actos de campaña del MOIR, el primer grupo maósta que se presentó a elecciones (1972). César Mora dice que

Empezamos a coger cierta fama y varias casas disqueras nos ofrecieron grabar. No pudimos hacerlo porque para la mentalidad estrecha de las políticas partidistas eso era venderse al comercio. No importaba que Alí Primera y otros muchos lo hubieran hecho. Nos decían que no se podía. Y no nos dejaron. ${ }^{43}$

En Cali había un chiste para dividir a la izquierda, de acuerdo con sus gustos musicales: a los del Partido Comunista les gustaba la música andina; a los del ML, los bambucos; a los trotskistas, la música clásica; y a los del MOIR, la salsa. A estos últimos, modestia aparte, yo fui el primero que les metió la música antillana. ${ }^{44}$

La aspiración de cualificarse como actores y como músicos, la instrumentalización de su trabajo en las campañas electorales y la necesidad de conseguir recursos para la subsistencia llevó a que tanto el Teatro Libre como el Son del Pueblo se independizaran del MOIR una década después de su fundación.Varios de sus integrantes han continuado su labor actoral en televisión y teatro, y en el mundo de la salsa. La temprana deriva hacia la música antillana o el teatro de autor, no tanto por razones ideológicas, sino por factores personales, y la desconexión con el mundo campesino los alejó del ideario maósta de una "música nacional".

41. "Los cantos del cañal”, Bogotá, [1976]. APCMB, Bogotá, casete, Pioneer N1a-60, 194 A.

42. Sandro Romero Rey, "César Mora: el camarada salsero", ;Fuera zapato viejo! Crónicas, retratos y entrevistas sobre la salsa en Bogotá, ed. Mario Jursich Durán (Bogotá: Instituto Distrital de las Artes / Instituto Distrital de Patrimonio Cultural / El Malpensante, 2014) 127.

43. Romero Rey 126.

44. Romero Rey 121. 


\subsection{Música campesina procesada en Bogotá}

La disidencia maoísta del PCC (1964) se ubica inicialmente, y de forma coherente con su pensamiento, en zonas campesinas, especialmente en el Magdalena Medio y la costa norte de Colombia. Por esta razón no hizo presencia en la vida cultural de Bogotá en esos años. Al igual que sucedió con otras tendencias, privilegió el teatro a otras expresiones artísticas. En 1968 se creó en Medellín (por su posición estratégica hacia el Magdalena Medio y la Costa Caribe) y luego en Cali el Frente Común para el Arte y la Literatura (FRECAL) dirigido por Fausto Cabrera (1924-2016). Cabrera, a diferencia de la falta de orientación en el PCC, difunde unos lineamientos claros y explícitos tomados de las Intervenciones del foro de Yenán de Mao. ${ }^{45}$

Por esta misma época, en el entorno de la Universidad Nacional en Bogotá, surgieron dos iniciativas que tuvieron orígenes, vinculaciones y militancias diversas, las cuales en algunos breves momentos se entrecruzaron, y que tendrían gran repercusión en años posteriores: el trabajo de Jorge Velosa y varios de los grupos en los que participó o lideró, y el grupo Nueva Cultura.

\subsubsection{Jotaele, Sayuna y Los Carrangueros}

Jorge Luis Velosa Ruiz (Ráquira, Boyacá, 1949), Jotaele como se le conocía en esa época, médico veterinario de la Universidad Nacional, en su época de estudiante participó en varios grupos de música y a inicios de los setenta ya había compuesto una serie de canciones en ritmos campesinos y costeños que mostraban un gran acercamiento al vocabulario y a la sensibilidad campesina cundiboyacense. Hacia 1973 hizo una grabación casera de sus canciones en un casete de 90 minutos, acompañado únicamente por su tiple o guitarra, que se reprodujo de mano en mano y que fue, sin lugar a dudas, el más escuchado por los universitarios y militantes de la izquierda en esa década. ${ }^{46}$ Sus letras se reprodujeron en todos los cancioneros de la época, ${ }^{47}$ se cantaban en las carpas de los huelguistas, en actos escolares, en marchas, en tomas de tierras, en barrios populares y en conciertos de la mayoría de los grupos vinculados a la izquierda. Las dos canciones icónicas eran "La lora proletaria" (rumba), de tono jocoso, y "Pueblo, pueblo colombiano" (pasillo). Aunque sus canciones eran las más populares entre la izquierda en la década de los setenta, no se encuentra una mención a él en la prensa ni en las numerosas revistas culturales de la época, ni tampoco daba conciertos masivos y publicitados.

Después de un breve paso por el Yaki Kandru, junto con otros estudiantes conforma el grupo Sayuna (en lengua kogui significa “origen”), con el que interpretaban repertorios indígenas, canciones latinoamericanas, campesinas colombianas

45. Parra Salazar 120.

46. APCMB, Bogotá, casete marcado con J.L.V., Lebotone LC-90, 196-133-134.

47. El cancionero del Instituto Nacional Sindical, en su edición de 1977, ligado ideológicamente al maoísmo, se titula $\mathrm{Pa}^{\prime}$ qué aguantar tanto, igual que un poema de Velosa, y le dedica una sección completa bajo el título "Canciones y poesías de Jotaele". 
y de Velosa. El grupo duró poco, pero sirvió de modelo para grupos como Canto al Pueblo (1977-1979) ${ }^{48}$ y Canta Libre (1976-1980). ${ }^{49}$

Velosa invita a algunos de los integrantes de Sayuna y Canta Libre al Concurso Guitarra de Plata Campesina en 1979, un concurso de música guasca (voces, guitarra puntera, acompañante, marcante o bajo y guacharaca o maracas) organizado por Radio Furatena de Chiquinquirá. Se presentan con algunas de las nuevas canciones de Velosa. Son declarados fuera de concurso y el gerente de la emisora les propone que hagan un programa de música campesina.

El programa se llamó Canta el pueblo, un magazín donde cantaban e invitaban a los campesinos a enviar relatos, coplas, canciones, refranes; ellos mismos, grabadora en mano, recorrían elValle de Ubaté recogiendo historias y tonadas. ${ }^{50}$

Velosa (voz, riolina —armónica - y guacharaca), Javier Moreno (de Bogotá, tiple requinto), Ramiro Zambrano (de Santander, guitarra) y Javier Apráez (de Nariño, tiple) se denominan para el programa de radio Los Carrangueros de Ráquira. ${ }^{51}$ Su popularidad va en aumento en el área de influencia de la emisora. Los ritmos que interpretaban eran los mismos que ya había explorado Velosa en su casete de estudiante, y las canciones eran una prolongación de lo que venía haciendo, pero con nuevas temáticas referidas a la cotidianidad campesina. La canción "La cucharita" (J.Velosa) se convierte pronto en un éxito en la región. En 1980 graban su primer LP con 10 canciones de Velosa y una composición del grupo, el cual sale prensado en 1981. Se había creado un nuevo género de la música campesina, "la carranga", que articuló influencias del merengue y paseo vallenatos, de la rumba criolla, del joropo, del bambuco, del pasillo, de la música parrandera antioqueña, del torbellino y la guabina. ${ }^{52}$ Los Carrangueros se disuelven en 1982 después de

48. Carlos Miñana Blasco y Grupo Armadillo, Cante compañero. Armadillo, vol. 4 (Bogotá: Dimensión Educativa, casete, 1986).

49. Integrantes de Canta Libre fueron, entre otros, Javier Moreno Forero (1951-1985, quien luego integraría Los Carrangueros) e Iván Benavides (1957, quien también tocó con Los Carrangueros a inicios de 1979 y posteriormente se convertiría en productor musical de Carlos Vives y Chocquibtown).

50. Claudia Alejandra Carrasco Benavides, "Sabores carrangueros: pasado, presente y popularización de la música carranguera en Colombia" (Tesis de pregrado en Antropología, Universidad Nacional de Colombia, 2011) 31.

51. La instrumentación provenía de los conjuntos campesinos de casi todo el país, conformados por tres guitarras (puntera, acompañante y marcante) y unas maracas o guacharaca, y de los conjuntos campesinos de Santander (tiple requinto, tiple acompañante, guitarra y percusión). Carlos Miñana Blasco y Egberto Bermúdez, "Colombia: Modern and Contemporary Performance Practice", The SAGE International Encyclopedia of Music and Culture, vol. 2, ed. Janet Sturman (London: SAGE, 2019) 585-589. En la página https://www.facebook.com/javiermorenoforeroelrequintista/ pueden verse varias fotos de Los carrangueros de esta primera época, antes del éxito comercial y de la grabación discográfica, en escenarios campesinos.

52. Sobre la carranga hay ya más de 15 tesis, lo cual muestra la importancia del fenómeno. Algunas de las primeras: Elizabeth Muñoz Yánez, "Merengue andino nor-oriental colombiano" (Tesis de pregrado en Pedagogía Musical, Universidad del Cauca, 1990), de la que fui director; Luis Ernesto Moreno Torres, "Los aires carrangueros: organización y análisis" (Tesis de pregrado en Pedagogía Musical, Universidad Pedagógica Nacional, 1997); Renato Paone, "La música 
grabar tres elepés. El fenómeno de la música carranguera puso en primer plano instrumentos que estaban próximos a desaparecer en la región, como el tiple requinto, y se convirtió en un fenómeno cultural de amplias dimensiones que tuvo también su presencia en seriados de televisión, y llegó a la "carranga sinfónica”, y que pervive hasta hoy.

\subsubsection{Una Nueva Cultura}

La segunda iniciativa, la más ambiciosa en su concepción y la que mostraba mayor coherencia y articulación ideológica e interdisciplinaria, resultó en torno a La Liga ML (1972). La Liga "retomaría más ortodoxamente las tesis maoístas y hablaría de una revolución de Nueva Democracia en la que jugaría papel una supuesta burguesía nacional"; logra una importante influencia en grupos campesinos y en la Asociación Nacional de Usuarios Campesinos (ANUC). La Liga "no conforma un grupo guerrillero, y [...] participa en las elecciones a las que acude primero por intermediarios y luego con candidatos propios en alianza con el MOIR". ${ }^{53}$

En torno a la Asociación Nacional de Teatro (ASONATE, fundada en 1975), se agrupan en Bogotá el Nuevo Taller Teatral de la Universidad Distrital, dirigido por Paco Barrero; el grupo de danzas Kari chipur — Canto Rojo-, con José Antonio Durán; por el lado musical un pequeño grupo de estudiantes de la Universidad Nacional — sin formación musical— conforman el grupo Nueva Cultura (1976), bajo el liderazgo de Enrique Sanabria T. (1956); pronto se vinculan Jorge Sossa (1956), Néstor Lambuley (1956) y, poco después, María Teresa “Mayté” Ropaín (1953).

Un evento fundamental para los grupos musicales de las disidencias del PCC fue el Primer Encuentro de la Canción Revolucionaria en Cali (Universidad del Valle) del 9 al 12 de octubre de 1976. Asistieron 25 grupos de todo el país;Velosa, el Yaki y Canta Libre también participaron. Profesores universitarios y líderes políticos fueron a "tirar línea", a posicionar en el debate la orientación ideológica. Los organizadores fueron el Comité Cultural Máximo Gorki (trotskista) y, obviamente, participó el líder y compositor Kemel George.

Después del evento, el grupo Taller Teatral de la Universidad Distrital, el Kari chipur, el grupo de canciones populares Nueva Cultura y un grupo de música a imitación del Yaki, Huella, se constituyen en la Brigada Nueva Cultura (19771979), ${ }^{54}$ y crean un espectáculo interdisciplinario denominado El enganche (1977) sobre los jornaleros temporeros. La temática permitía mostrar la explotación del campesinado sin tierra al mismo tiempo que la diversidad cultural del país rural. La canción final, compuesta por Enrique Sanabria, fue grabada posteriormente y dio el título al primer LP del grupo, titulado Nuestra cosecha (1980).

carranguera" (Tesis de pregrado en Música, Escuela Popular de Arte, 1999).

53. Archila, "El maoísmo" 158.

54. Ochoa Gautier 151-152. 


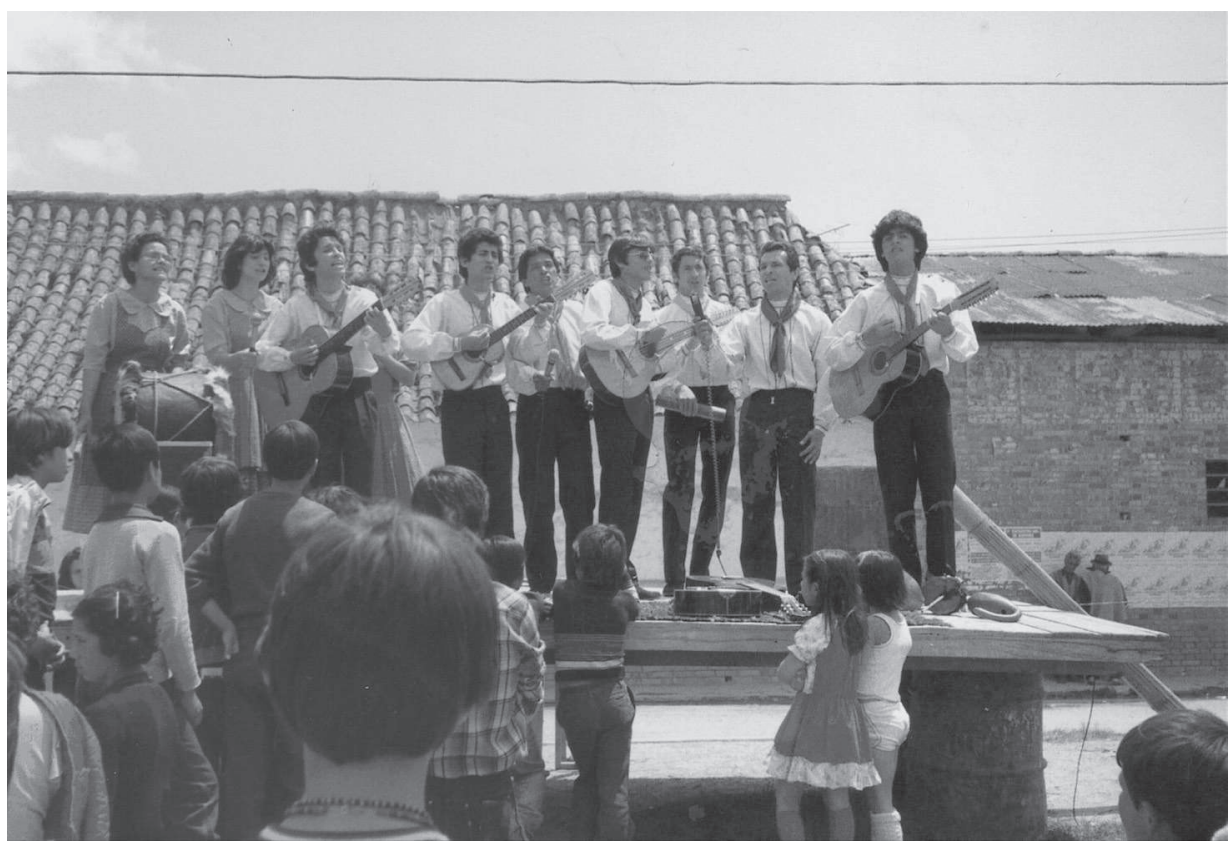

Fuente: “Requinto, dos tiples, guitarra, tambora y 'percusión menor’ sonando y en el piso (chucho, güiro, marrana, cucharas, quiribillos...)”. [Bogotá], 1979. AFNC, Bogotá.

A finales de 1977 los fundadores de Nueva Cultura se retiran, lo cual lleva a los que quedaban (Sossa, Lambuley y Ropaín) a asumir con mayor compromiso el quehacer musical y cultural y a conseguir nuevos integrantes (Figura 1). Separan los ensayos de la formación política, que la asume la Brigada. Ese año inician las salidas de campo "como necesidad de buscar material, no queríamos cantar lo que cantaba todo el mundo": 55

Tanto Sossa como Lambuley, líderes del grupo, inician un plan sistemático de estudios con músicos profesionales. La relación más fructífera y prolongada (19801993) va a ser con Samuel Bedoya Sánchez (1947-1994). ${ }^{56}$

A diferencia de otras agrupaciones de las disidencias del PCC desde el comienzo la Brigada quiso impactar en los medios, especialmente en televisión y en radio (Paco Barrero era director de televisión). Radio Todelar emitió el programa "Raíces y horizontes de la cultura popular en Colombia. Programa de divulgación de los valores culturales del pueblo colombiano, por su defensa y desarrollo" con libretos dramatizados y música en vivo. Con una duración de una hora, se transmitió los domingos durante 75 semanas, lo cual demandó gran cantidad de trabajo,

55. Entrevista de Carlos Miñana Blasco a Jorge Sossa, Bogotá, 30 de diciembre de 2015.

56. Néstor Lambuley Alférez, Samuel Bedoya Sánchez: vida y obra (Bogotá: Instituto Departamental de Cultura del Meta, 2014). 
pero también se convirtió en una escuela que permitió a Nueva Cultura investigar, conocer y practicar la música de todo el país. ${ }^{57}$

En 1977 imprimen un cancionero ${ }^{58}$ con su repertorio que incluía, además de los himnos obligados como "La internacional", varias canciones de Jotaele, tonadas llaneras, de torbellino, guabina y rajaleñas con coplas escogidas o modificadas para alinearlas ideológicamente, canciones de la ANUC, de Manuel Orozco (1949), de la nueva canción latinoamericana y algunas compuestas por Kari chipur y por el grupo.

El Nueva Cultura se presentó al Primer Concurso de Intérpretes de Música Típica Colombiana (1979, COLCULTURA), para lo cual grabó un demo. Su propuesta se distanciaba tanto de lo que normalmente se consideraba música colombiana como de la música folklórica que se presentaba en los numerosos festivales y concursos regionales. Ganó el premio de la modalidad ConjuntoVocalInstrumental, Zona Andina el 22 de noviembre de 1980. Desde COLCULTURA se organizó también Noches de Colombia (1981-1983), ciclo de conciertos en el Teatro Colón —antes reservado a la música clásica- que tuvo gran impacto, pues fueron transmitidos en vivo por la televisión nacional. Los Carrangueros y el Nueva Cultura se presentaron en el concierto inaugural el 28 de febrero de $1981 .{ }^{59}$

Impulsados por el concurso graban su primer LP independiente, Nuestra cosecha (1980), con 10 canciones, dos de ellas basadas en tonadas tradicionales (guabina y rajaleñas) con coplas adaptadas por el Nueva Cultura. Las otras ocho canciones son composiciones de integrantes del grupo o cercanos a él.

El intenso ritmo de trabajo del Nueva Cultura entró en conflicto con las "tareas" propias del activismo político. En la organización les decían que tanto tiempo dedicado a la música era "autocultivo pequeñoburgués", a lo que respondían que "nuestra célula es el ensayo", "la cosa es tocando y tocando bien”. En 1982 se produce una ruptura definitiva con la organización política. ${ }^{60}$

La trayectoria posterior del grupo Nueva Cultura es bien conocida tanto en el campo musical como en la organización de encuentros y congresos de música, en la pedagogía musical infantil y en la formación musical en la educación superior. Lideraron un programa universitario en torno a las "músicas caribes iberoamericanas" (CIAM).

Si en otros grupos se sentía de alguna forma una disciplina, un compromiso, y una autoridad proveniente de la "militancia", en el Nueva Cultura esto fue mucho más evidente, como se aprecia en los informes de los encuentros y festivales, en los ensayos, en los arreglos y montajes musicales, en los libretos. A diferencia de los otros grupos, el Nueva Cultura trabajó con partituras ("arreglos compositivos",

57. En el archivo de la Fundación Nueva Cultura se encuentran los libretos mecanografiados de casi todos los programas y uno de los actos de El enganche. Agradezco a Mayté Ropaín de la Fundación Nueva Cultura el acceso al archivo, así como las entrevistas a Mayté Ropaín, Jorge Sossa y Alberto Aljure.

58. Grupo musical Nueva Cultura, Canciones del pueblo (Bogotá:ASONATE, 1977).

59. "Noches de Colombia”, Hagamos cultura (Bogotá) 1981.

60. Ochoa Gautier 159. 
decían) en los que se detallaba hasta la "percusión menor". Por el trabajo musical durante todos esos años los integrantes no recibieron remuneración alguna.

La opción estética del Nueva Cultura por la música popular colombiana, por las músicas campesinas y regionales se ha mantenido hasta hoy: "Lo nacional como base, lo extranjero como condición. Vamos a trabajar lo nuestro, nuestra tierra, nuestras raíces, somos Colombia, conozcamos lo que tenemos". ${ }^{61}$

\section{Conclusiones}

El planteamiento maoísta de la nueva democracia implicaba un trabajo de masas de larga duración, e incluso la colaboración con la pequeña burguesía; el "atraso" de Colombia aún con formas económicas feudales, exigía un largo proceso de "elevación" de la conciencia y de la cultura de los sectores populares. Esta concepción llevó a los grupos afines al maoísmo a comprometerse en proyectos de divulgación, discográficos y mediáticos, algo inconcebible en épocas anteriores marcadas por el foquismo guerrillero y donde se percibía la inmediatez en la toma del poder.

A diferencia de la mayoría de los grupos musicales de la época, estas dos iniciativas - como el Yaki- no dependieron del teatro, lo cual dio una mayor autonomía a lo musical. El trabajo de campo, el aprender la música de los campesinos, va a generar una serie de productos investigativos aplicados como los de la Escuela Popular de Arte y Canchimalos (1976) en Medellín y el proyecto pedagógico e investigativo del Nueva Cultura en la Academia Luis A. Calvo y en la Universidad Distrital en Bogotá.

En una fase inicial los grupos montaban la música lo más parecido a la grabación de campo, pero se modificaban un poco los textos "para elevar el nivel de conciencia” del pueblo. Los conciertos eran didácticos, se hacían demostraciones de los instrumentos, se remedaba el lenguaje popular, se alababa la riqueza de la música campesina e indígena, se denunciaba la explotación. Sin embargo, a finales de los setenta los conciertos reducen los discursos y su carácter didáctico y político. Los textos son nuevas creaciones poéticas que reflejan la cotidianidad de los campesinos, o poemas de poetas profesionales. El Nueva Cultura puso el acento en la cualificación y transformación de lo musical, y Velosa de la poética y de las temáticas.

La ruptura con el folklorismo y con la figura emblemática de Guillermo Abadía, que había inspirado a todos en un comienzo, se dio públicamente en 1981, ${ }^{62}$ desmarcando su trabajo no solo de la música colombiana, sino también de la música folklórica. Obviamente, la música que ellos hacían era una versión urbana, universitaria, pero mucho más cercana a las prácticas campesinas vigentes. Estas en Colombia son muy colectivas y participativas diferentes al payador, al cantautor inspirado, tan común en la nueva canción latinoamericana; los cantautores

61. Entrevista de Carlos Miñana Blasco a Alberto Aljure, Bogotá, 2018. En la página web oficial del Nueva cultura https://www.gruponuevacultura.com/ pueden verse fotos y escuchar grabaciones de diferentes épocas del grupo.

62. Miñana Blasco, "Entre el folklore". 
únicamente estuvieron en Bogotá al comienzo de la canción protesta (nadaísmo, PCC y socialismo), reaparecieron a mediados de los ochenta como imitadores de Silvio Rodríguez en las tabernas bogotanas y tenían poco que ver con el ideario maoísta.

El nacionalismo se expresó también en la recuperación del instrumental colombiano; varios de estos músicos se dedicaron a la lutería y sofisticaron los instrumentos tradicionales y su ejecución. Hasta hoy, El Nueva Cultura, Velosa y el Yaki se han mantenido con una sonoridad acústica, una opción claramente política que tiene que ver con la autonomía tecnológica y la cultura nacional.

Músicos y músicas circularon entre todos estos grupos y enriquecieron sus perspectivas:Velosa integró el Yaki, Catana del Yaki integró el Sayuna de Velosa y grabó con él su cuarto LP, Jorge López grabó canciones de Velosa en Alemania; el Nueva Cultura tocaba canciones de Velosa, pero Guafa y Jorge González, del Nueva Cultura, tocaron con Velosa varios años. Los exintegrantes e imitadores de estos grupos han creado a su vez nuevas agrupaciones con estéticas y políticas diferentes, pero han conservado su impronta inicial: el enraizamiento en el mundo campesino de Los Carrangueros, la rigurosidad en el abordaje de las músicas colombianas del Nueva Cultura y muchas de las opciones estéticas que se tomaron en esta década.

A pesar de las numerosas evidencias de los vínculos entre música y política, esta época nos muestra también la importancia de factores fortuitos y estrictamente personales, como sucedió con Son del Pueblo en el que las trayectorias y opciones estéticas personales lograron imponerse al ideario político.

La década de los setenta, lejos de ser una "década perdida", muestra que al calor de los debates ideológicos de la izquierda se forjaron una serie de propuestas que han tenido continuidad hasta hoy. Estos grupos crearon nuevos públicos abiertos a nuevas sonoridades y a la diversidad de la música colombiana. ${ }^{63}$

Miguel Ángel Urrego sostiene que la década de 1980 significó la "cooptación de los intelectuales disidentes". ${ }^{64}$ Tal vez tenga razón, pero también fue la eclosión, la visibilización y el posicionamiento nacional e internacional de una serie de propuestas musicales que se habían gestado en la década anterior y que no fueron visibles en la prensa ni en la producción discográfica.

\section{Fuentes}

\section{Audiovisuales}

Archivo de la Fundación Nueva Cultura, Bogotá (AFNC)

Archivo Personal de Carlos Miñana Blasco, Bogotá (APCMB)

63. Una evidencia del reconocimiento de estos grupos fue su inserción en 1987 en la colección más ambiciosa de música colombiana: Música Tradicional y Popular Colombiana, dirigida por Egberto Bermúdez (Procultura), en el décimo LP, Canto mestizo, dedicado a las "nuevas tendencias".

64. Urrego Ardila. 


\section{Orales}

Aljure, Alberto, entrevista realizada por Carlos Miñana Blasco. Bogotá, 2018.

Sossa, Jorge, entrevista realizada por Carlos Miñana Blasco. Bogotá, 30 de diciembre de 2015.

\section{Periódicos y revistas}

El Tiempo (Bogotá) 1979.

Tribuna Roja (Bogotá) 1971-1984.

\section{Bibliografía}

Archila Neira, Mauricio. "El maoísmo en Colombia: La enfermedad juvenil del marxismo-leninismo”. Controversia 190 (2008): 147-196.

. Idas y venidas, vueltas y revueltas. Protestas sociales en Colombia, 1958-1990. Bogotá: Instituto Colombiano de Antropología e Historia, 2003.

Ayala Diago, César Augusto. "Colombia en la década de los años setenta del siglo XX". Anuario Colombiano de Historia Social y de la Cultura 30 (2003): 319-338.

Bermúdez, Egberto. "From Colombian 'National Song' to 'Colombian Song': 1860-1960”. Lied und Populäre Kultur / Song and Popular Culture 53 (2008): 167-261.

Carrasco Benavides, Claudia Alejandra. "Sabores carrangueros: pasado, presente y popularización de la música carranguera en Colombia”. Tesis de pregrado en Antropología, Universidad Nacional de Colombia, 2011.

Gac Artigas, Gustavo y Perla Valencia Moncada. Antología de canción protesta. Bogotá: Editorial Colombia Nueva, 1970.

García Barrientos, Federico. Publicidad, rock and roll, contracultura y política: Colombia 1967-1974 (del giro del consumo al del mercado electoral). Medellín: Universidad Pontificia Bolivariana, 2016.

García González, David Fernando. "Bandas sonoras de la colombianidad. Un estudio de los íconos musicales de la nación en el siglo XXI”. Tesis de doctorado en Ciencias Humanas y Sociales, Universidad Nacional de Colombia, 2016.

García Velandia, Martha Cecilia. "El presente es de lucha: el futuro, socialista”. Controversia 190 (2008): 97-145.

González Rodríguez, Juan Pablo. Pensar la música desde América Latina. Problemas e interrogantes. Santiago: Ediciones Universidad Alberto Hurtado, 2013. . "Musicología popular en América Latina: síntesis de sus logros, problemas y desafios". Revista musical chilena 195 (2001): 38-64.

González Rodríguez, Juan Pablo y Claudio Rolle. "Cristalización genérica en la música popular chilena de los años sesenta”. Música popular en América Latina. Actas del II Congreso Latinoamericano IASPM. Ed. Rodrigo Torres. 
Santiago: IASPM, 1999.

Grupo musical Nueva Cultura. Canciones del pueblo. Bogotá:ASONATE, 1977.

Guerrero Pérez, Juan José. La canción protesta latinoamericana y la Teología de la Liberación: estudio de género musical y análisis de vínculo sociopolítico y religioso (1968-2000). Caracas: Monte Ávila, 2005.

Hernández Ortiz, Rodolfo Antonio. “Los orígenes del maoísmo en Colombia: la recepción de la Revolución de Nueva Democracia 1949-1963”. Tesis de pregrado en Historia, Universidad Nacional de Colombia, 2016.

Katz-Rosene, Joshua. "From Protest Song to Social Song: Music and Politics in Colombia, 1966-2016”. PhD dissertation in Music, City University of New York, 2017.

. "Discourse in Música Latinoamericana Cultural Projects from Nueva Canción to Colombian Canción Social’. Volume! 11.2 (2015): 65-83.

Lambuley Alférez, Néstor. Samuel Bedoya Sánchez: vida y obra. Bogotá: Instituto Departamental de Cultura del Meta, 2014.

León Palacios, Paulo César. "Una experiencia estética de lo político: el teatro en Bogotá durante los años 1960 y 1970". Historelo. Revista de Historia Regional y Local 9.17 (2017). DOI: 10.15446/historelo.v9n17.54732 $(17 / 02 / 2018)$.

Maldonado C., Claudia María. "La Candelaria de Bogotá en el paisaje teatral colombiano". Memoria de Master investigativo, Université SorbonneNouvelle, Paris III, 2005.

Miñana Blasco, Carlos. "Entre el folklore y la etnomusicología. Sesenta años de estudios sobre música popular tradicional en Colombia”. A Contratiempo. Revista de música en la cultura 11 (2000): 36-49.

Miñana Blasco, Carlos y Egberto Bermúdez. "Colombia: Modern and Contemporary Performance Practice". The SAGE International Encyclopedia of Music and Culture.Volumen 2. Ed. Janet Sturman. London: SAGE, 2019.

Miñana Blasco, Carlos y Grupo Armadillo. Cante compañero. Armadillo. Volumen 4. Bogotá: Dimensión Educativa, 1986.

Molano Camargo, Frank. "El campo es leña seca lista para arder. La Liga Marxista Leninista de Colombia, 1971-1982”. Anuario Colombiano de Historia Social y de la Cultura 44.2 (2017): 137-170.

Moore, Robin D. Music and Revolution. Cultural Change in Socialist Cuba. Berkeley: University of California Press, 2006.

Moreno Torres, Luis Ernesto. “Los aires carrangueros: organización y análisis”. Tesis de pregrado en Pedagogía Musical, Universidad Pedagógica Nacional, 1997.

Moure de Ramírez, Consuelo. "El teatro universitario colombiano 1968-1975”. Ensayo, Escuela Nacional de Arte Dramático, 1989.http://es.scribd.com/ doc/201382621/El-Teatro-Universitario-Colombiano-1968-1975 (04/02/2018).

Múnera Ruiz, Leopoldo. Rupturas y continuidades: poder y movimiento popular en Colombia, 1968-1988. Bogotá: Universidad Nacional de Colombia, 1998. 
Muñoz Yánez, Elizabeth. "Merengue andino nor-oriental colombiano”. Tesis de pregrado en Pedagogía Musical, Universidad del Cauca, 1990.

Ochoa Gautier, Ana María. "Plotting Musical Territories. Three Studies in Processes of Recontextualization of Musical Folklore in the Andean Region of Colombia”. PhD dissertation in Ethnomusicology and Folklore, Indiana University, 1996.

Paone, Renato. "La música carranguera”. Tesis de pregrado en Música, Escuela Popular de Arte, 1999.

Parra Salazar, Mayra Natalia. ;A teatro camaradas! Dramaturgia militante y política de masas en Colombia (1965-1975). Medellín: Fondo Editorial FCSH, 2015.

Restrepo Duque, Hernán. Lo que cuentan las canciones: cronicón musical. Bogotá:Tercer Mundo, 1971.

Rios, Fernando. "La Flûte Indienne: The Early History of Andean Folkloric-Popular Music in France and its Impact on Nueva Canción". Latin American Music Review / Revista de Música Latinoamericana 29.2 (2008): 145-181.

Robayo Pedraza, Miryam Ibeth. "La canción social como expresión de inconformismo social y político en el siglo XX”. Calle 14 10.16 (2015): 54-67.

Romero Rey, Sandro. "César Mora: el camarada salsero”. ¡Fuera zapato viejo! Crónicas, retratos y entrevistas sobre la salsa en Bogotá. Ed. Mario Jursich Durán. Bogotá: Instituto Distrital de las Artes / Instituto Distrital de Patrimonio Cultural / El Malpensante, 2014.

Thornton, Sarah. "Strategies for Reconstructing the Popular Past". Popular Music 9.1 (1990): 87-95.

Tirado Mejía, Álvaro. Los años sesenta. Bogotá: Debate, 2014.

Tse-tung, Mao. Sobre la nueva democracia. Intervenciones en el foro de Yenán sobre arte y literatura. Sobre el tratamiento correcto de las contradicciones en el seno del pueblo. Discurso ante la Conferencia Nacional del Partido Comunista de China. Pekín: Ediciones en Lenguas Extranjeras, 1972.

Tumas-Serna, Jane. “The 'Nueva Canción' Movement and Its Mass-Mediated Performance Context". Latin American Music Review / Revista de Música Latinoamericana 13.2 (1992): 139-157.

Urrego Ardila, Miguel Ángel. Intelectuales, Estado y Nación en Colombia. De la guerra de los Mil Días a la constitución de 1991. Bogotá: Universidad Central, 2002. 